\title{
STERILISATION OF COLICINE PREPARATIONS
}

\author{
B. W. Senior, H. Richardson AND A. H. EmSlie-Smith \\ Department of Microbiology, University of Newcastle Medical School
}

THE sterilisation of colicine preparations is commonly achieved (i) by the addition of chloroform, (ii) by heating, or (iii) by filtration (Fredericq, 1963). It is now well recognised that no single method is ideally suited for use with all colicines, since some of these substances are heat-labile (Fastier, 1949; Hamon and Péron, 1961, 1963, 1964; Clarke and Macphee, 1965; Keene, 1966), others are damaged by chloroform (Kellenberger and Kellenberger, 1956; Hamon and Péron, 1959, 1966; Matsushita, Fox and Goebel, 1960; Papavassiliou, 1961), and most are adsorbed to filters (Heatley and Florey, 1946; Frederica, 1957; Mukai, 1960; Hauduroy and Papavassiliou, 1962). It has become the practice to sterilise each colicine by a procedure compatible with its particular physical and chemical properties. We consider that all sterilisation procedures involve some loss of colicine potency and that the extent of this loss is related to the initial colicine titre and the degree of purity of the colicine. For purely qualitative investigations this loss of colicine potency is not important, but for quantitative work such as our investigations of colicine production, it is desirable to know how much activity is lost by individual preparations during sterilisation. In the present study, we have determined the relative degrees of activity remaining in preparations from cultures containing colicines $\mathrm{A}, \mathrm{B}, \mathrm{D}$, $E_{2}, E_{3}$ and $K$ after samples of these preparations had been subjected to one of the following manipulations: (i) heating at different temperatures for different periods, (ii) addition of chloroform, (iii) filtration, and (iv) exposure to ultraviolet light.

\section{MATERIALS AND METHODS}

Strains. Colicine-producing cultures of Escherichia freundii strain CA31 (colicine A) and of Esch. coli strains CA18 (colicine B), CA23 (colicine D), CA42 (colicine $\mathrm{E}_{2}$ ), CA38 (colicine $\mathrm{E}_{3}$ ), and $\mathrm{K} 235$ (colicine $\mathrm{K}$ ), and of Shigella sonnei strain $\mathrm{P}_{9}$ (colicine $\mathrm{E}_{2}$ ) were obtained from Professor P. Fredericq of the University of Liège. Other strains of Esch. coli producing colicine B (strains CL139, K260 and TR24) were provided by Dr Y. Hamon of the Pasteur Institute, Paris.

Esch. coli 9605 , a locally isolated strain, was used as the indicator organism for the assay of colicine-B activity. For all the other colicines examined, the indicator organism was a substrain of Esch. coli B obtained from the MRC Microbial Genetics Unit, Hammersmith Hospital, London.

Culture media and conditions for colicine production. Three different media were used for the growth of the colicinogenic bacteria: (i) peptone water containing $10 \mathrm{~g}$ of Oxoid bacteriological peptone and $5 \mathrm{~g}$ sodium chloride per litre; (ii) a minimal salts medium containing $3.0 \mathrm{~g} \mathrm{KH}_{2} \mathrm{PO}_{4}, 7.0 \mathrm{~g} \mathrm{~K}_{2} \mathrm{HPO}_{4}, 1.0 \mathrm{~g} \mathrm{NH}_{4} \mathrm{Cl}, 0.1 \mathrm{~g} \mathrm{MgSO}_{4} .7 \mathrm{H}_{2} \mathrm{O}$ and $10 \mathrm{~g}$ sodium lactate in 1 litre of distilled water; and (iii) a medium with the same salts composition as the minimal

Received 14 Oct. 1969; accepted 27 Feb. 1970.

J. MED. MICROBIOL.-VOL. 3 (1970) 
medium, but supplemented with the dialysates of $9.0 \mathrm{~g}$ Oxoid yeast extract and $9.0 \mathrm{~g}$ Difco casamino acids in each litre. The media were dispensed in $150-\mathrm{ml}$ amounts in $250-\mathrm{ml}$ conical flasks.

Fluid cultures for colicine production were seeded from stock agar slant cultures of the colicinogenic strains. The cultures were incubated at $37^{\circ} \mathrm{C}$ for $48 \mathrm{hr}$ in a Gyrotory shaker incubator (New Brunswick Scientific Company, New Jersey).

Assay of colicine potency. The colicine preparations were assayed by an agar diffusion method (Richardson, Emslie-Smith and Senior, 1968). In each experiment the preparation that had received least manipulation was examined at three concentrations: usually undiluted and diluted 1 in 2 and 1 in 4 . The activity of any other preparation assayed on the same plate was calculated in terms of the potency of the undiluted minimally treated preparation, which served as the arbitrary standard for that experiment.

In the text, the activity of any one colicine preparation is expressed as a percentage of the potency of the most active preparation in the experiment. In the tables, actual experimental data are recorded as the mean diameters of inhibition zones produced in the assay indicator lawn by appropriate volumes of individual preparations.

\section{Sterilisation methods}

Sterilisation by heat. With sterile medium as the diluent, doubling dilutions were prepared from one-half of each colicine-containing culture; the other half was centrifuged at $2300 \mathrm{~g}$ for $15 \mathrm{~min}$. and similar dilutions were made from the supernatant fluid. Convenient volumes $(10 \mathrm{ml})$ of both series of dilutions were heated in a waterbath at predetermined temperatures within the range $50^{\circ}-100^{\circ} \mathrm{C}$ for up to $60 \mathrm{~min}$. After exposure to heat, the dilutions prepared from the cultures were centrifuged at $2300 \mathrm{~g}$ for $15 \mathrm{~min}$. and the supernatant fluids were collected. The treated preparations were stored aseptically in glass bottles at $4^{\circ} \mathrm{C}$.

Sterilisation by filtration. Supernatant fluids from the colicine active cultures were filtered through sterile Seitz filters fitted with Ford Sterimats, grade SB, of $3.6 \mathrm{~cm}$ diameter (T. B. Ford Ltd, High Wycombe, Bucks). Similar samples were filtered through Millipore membrane filters (Millipore U.K. Ltd, Wembley, Middx) of $0.45 \mu \mathrm{m}$ porosity; the sterile filtrates were collected fractionally, $2 \mathrm{ml}$ at a time, and the fractions were stored at $4^{\circ} \mathrm{C}$ until required.

Sterilisation by chloroform. Chloroform was added to cultures containing colicine to give a final concentration of chloroform of about 5 per cent. $(\mathrm{v} / \mathrm{v})$. The bottles were thoroughly shaken and samples were removed after 5, 15, 30 and $60 \mathrm{~min}$. The samples were centrifuged at $2300 \mathrm{~g}$ for $15 \mathrm{~min}$. or for the minimum time to give a clear supernatant fluid. The clear fluids were transferred to loosely capped sterile bottles and incubated at $37^{\circ} \mathrm{C}$ for $1 \mathrm{hr}$ to remove residual chloroform. After tightening the caps, we stored the bottles at $4^{\circ} \mathrm{C}$.

Sterilisation by ultraviolet irradiation. A Philips TUV 15W lamp was used at a distance of $50 \mathrm{~cm}$ to irradiate 10- $\mathrm{ml}$ amounts of culture supernatant in petri dishes of $9 \mathrm{~cm}$ diameter. The samples were gently agitated during the period of irradiation, which lasted for $5,15,30$ or $60 \mathrm{~min}$. The irradiated samples were decanted into sterile bottles and stored at $4^{\circ} \mathrm{C}$ until required.

\section{RESULTS}

When cultures of the same organism in different media were examined, the effects of each sterilising procedure on colicine activity were always similar and were uninfluenced by the type of medium in which the colicine had been produced. For this reason, only one representative set of results is presented and discussed below.

\section{Effect of sterilisation by heat on colicine potency}

The supernatant fluids from all the cultures showed some progressive loss of colicine activity after heating; this loss was most marked with colicine $\mathrm{B}$, and 
least with colicines $\mathrm{D}, \mathrm{E}_{2}$ and $\mathrm{E}_{3}$. The results of typical experiments are presented in table I.

Preparations of colicine B, from Esch. coli strains CA18, CL139 and TR24, all showed slight loss in potency after heating at $60^{\circ} \mathrm{C}$ for $20 \mathrm{~min}$., a much more marked loss after $5 \mathrm{~min}$. at $80^{\circ} \mathrm{C}$, and loss of all activity after exposure to $100^{\circ} \mathrm{C}$.

TABLE I

Colicine activity of six test preparations after exposure to heat at different temperatures for varying lengths of time

\begin{tabular}{|c|c|c|c|c|c|c|c|}
\hline \multirow{2}{*}{$\begin{array}{l}\text { Temperature } \\
\left({ }^{\circ} \mathrm{C}\right)\end{array}$} & \multirow{2}{*}{$\begin{array}{l}\text { Time of } \\
\text { exposure } \\
\text { (min.) }\end{array}$} & \multicolumn{6}{|c|}{ Colicine activity* of test preparation } \\
\hline & & $\mathrm{A}-\mathrm{CA} 31 \uparrow$ & B-CA18 & D-CA23 & $\mathrm{E}_{2}-\mathrm{CA} 42$ & $\mathrm{E}_{3}-\mathrm{CA} 38$ & $\mathrm{~K}-\mathrm{K} 235$ \\
\hline 60 & $\begin{array}{r}5 \\
12 \\
20 \\
60\end{array}$ & $\begin{array}{l}128 \\
123 \\
122 \\
116\end{array}$ & $\begin{array}{r}145 \\
147 \\
120 \\
96\end{array}$ & $\begin{array}{l}147 \\
145 \\
146 \\
145\end{array}$ & $\begin{array}{l}256 \\
257 \\
256 \\
247\end{array}$ & $\begin{array}{l}261 \\
265 \\
260 \\
256\end{array}$ & $\begin{array}{l}179 \\
174 \\
183 \\
175\end{array}$ \\
\hline 70 & $\begin{array}{r}5 \\
12 \\
20 \\
60\end{array}$ & $\begin{array}{l}117 \\
110 \\
107 \\
106\end{array}$ & $\begin{array}{r}122 \\
101 \\
0 \\
0\end{array}$ & $\begin{array}{l}143 \\
142 \\
140 \\
142\end{array}$ & $\begin{array}{l}247 \\
228 \\
230 \\
229\end{array}$ & $\begin{array}{l}260 \\
261 \\
257 \\
253\end{array}$ & $\begin{array}{l}186 \\
168 \\
161 \\
159\end{array}$ \\
\hline 80 & $\begin{array}{r}5 \\
12 \\
20 \\
60\end{array}$ & $\begin{array}{r}123 \\
112 \\
109 \\
93\end{array}$ & $\begin{array}{r}116 \\
0 \\
0 \\
0\end{array}$ & $\begin{array}{l}148 \\
145 \\
140 \\
144\end{array}$ & $\begin{array}{l}238 \\
237 \\
231 \\
226\end{array}$ & $\begin{array}{l}258 \\
253 \\
250 \\
246\end{array}$ & $\begin{array}{l}157 \\
138 \\
126 \\
113\end{array}$ \\
\hline 100 & $\begin{array}{r}5 \\
12 \\
20 \\
60\end{array}$ & $\begin{array}{r}94 \\
82 \\
0 \\
0\end{array}$ & $\begin{array}{l}0 \\
0 \\
0 \\
0\end{array}$ & $\begin{array}{r}150 \\
141 \\
128 \\
0\end{array}$ & $\begin{array}{l}242 \\
232 \\
230 \\
147\end{array}$ & $\begin{array}{l}235 \\
200 \\
173 \\
150\end{array}$ & $\begin{array}{r}117 \\
104 \\
102 \\
0\end{array}$ \\
\hline
\end{tabular}

* Colicine activity is expressed as the average diameter of four replicate inhibition zones recorded in $\mathrm{cm} \times 10^{-2}$

$\dagger$ The initial letter indicates the type of colicine; the subsequent letters and numerals identify the producer strain (see Methods).

Samples heated at $50^{\circ} \mathrm{C}$ or $55^{\circ} \mathrm{C}$ were not sterile even after $60 \mathrm{~min}$. at these temperatures. However, sterile preparations were always obtained after heating at $60^{\circ} \mathrm{C}$ for $5 \mathrm{~min}$. and, as the assay method is not suitable for living cultures, the potencies of these minimally treated sterile preparations were arbitrarily used as experimental standards.

The potency of a sample of a colicine-A preparation heated at $70^{\circ} \mathrm{C}$ for 5 min. was generally about 50 per cent. of that of the corresponding sample heated at $60^{\circ} \mathrm{C}$ for the same time. Further exposure to heat at $70^{\circ} \mathrm{C}$ for $60 \mathrm{~min}$. reduced this relative potency to approximately 25 per cent. After $5 \mathrm{~min}$. at $100^{\circ} \mathrm{C}$ there was an equivalent loss of activity and after $20 \mathrm{~min}$. at this temperature the preparation was inactive. Colicine $\mathrm{K}$ behaved similarly but seemed slightly more thermostable; the colicine activity in this experiment was not 
completely abolished until the specimen had been heated at $100^{\circ} \mathrm{C}$ for $60 \mathrm{~min}$.

Colicine $\mathrm{D}$ was the most thermostable of those investigated. There was no loss of activity when the preparations were heated at $80^{\circ} \mathrm{C}$ for up to $60 \mathrm{~min}$. After exposure to heat at $100^{\circ} \mathrm{C}$ for $5 \mathrm{~min}$. the preparations were as active as those heated at $60^{\circ} \mathrm{C}$ for $5 \mathrm{~min}$., but after exposure to heat at $100^{\circ} \mathrm{C}$ for $20 \mathrm{~min}$. the activity dropped to approximately 40 per cent., and it was abolished altogether after $1 \mathrm{hr}$.

Colicine $E_{2}$ behaved unusually in that there was a slight loss of activity after heating at $70^{\circ} \mathrm{C}$ for $20 \mathrm{~min}$., but further significant loss of potency occurred only after heating at $100^{\circ} \mathrm{C}$ for $60 \mathrm{~min}$. when the relative level of activity fell to 10 per cent. or lower. Colicine $\mathrm{E}_{3}$ was also thermostable until heated at $100^{\circ} \mathrm{C}$.

TABLE II

The effect of chloroform on colicine-B activity

\begin{tabular}{c|c|c|c|c}
\hline $\begin{array}{c}\text { Time of } \\
\text { exposure to } \\
\text { chloroform } \\
\text { (min.) }\end{array}$ & \multicolumn{3}{|c|}{ Colicine activity* of test preparation } \\
\cline { 2 - 5 } & B-CA18† & B-CL139 & B-K260 & B-TR24 \\
\hline 5 & $184 \cdot 3$ & $208 \cdot 7$ & $146 \cdot 3$ & $122 \cdot 6$ \\
15 & $168 \cdot 9$ & $200 \cdot 3$ & $132 \cdot 7$ & $117 \cdot 5$ \\
30 & $157 \cdot 3$ & $189 \cdot 1$ & $125 \cdot 0$ & $115 \cdot 2$ \\
60 & $151 \cdot 1$ & $182 \cdot 4$ & $123 \cdot 5$ & $114 \cdot 1$ \\
\hline
\end{tabular}

* Colicine activity is expressed as the average diameter of four replicate inhibition zones recorded in $\mathrm{cm} \times 10^{-2}$.

$\dagger$ As in footnote to table I.

\section{Effect of sterilisation by chloroform on colicine potency}

After exposure to chloroform for $5 \mathrm{~min}$., cultures of all of the strains were found to be sterile and colicine activity could be detected in the supernatant fluids of these cultures after several hours in the presence of chloroform.

Colicine-B preparations from cultures of four distinct strains were all progressively inactivated by exposure to chloroform (table II). The degree of inactivation appeared to be proportional to the amount of colicine present and to fall off exponentially with time. Nevertheless, as estimated from the diameters of the zones of inhibition, preparations of colicine B sterilised by exposure to chloroform for $5 \mathrm{~min}$. were generally more active than those sterilised by heat. Preparations from strain TR24 were exceptional, however, and were more sensitive to chloroform than to heat.

Colicine $\mathrm{K}$ resembled colicine $\mathrm{B} / \mathrm{TR} 24$, chloroform-treated preparations being less active than those sterilised by heat. Moreover, prolonged exposure to chloroform resulted in some progressive inactivation of colicine $\mathrm{K}$, but this effect was not as marked as with the B colicines.

Colicines $A, D, E_{2}$ and $E_{3}$ showed no loss of activity even after $60 \mathrm{~min}$. in the presence of an amount of chloroform greatly in excess of that required to sterilise the culture. Furthermore, colicine preparations of this group sterilised by the 
addition of chloroform were usually more active than corresponding preparations sterilised by heat.

\section{Effect of sterilisation by filtration on colicine potency}

When cultures containing colicine were filtered through Ford Sterimats, no colicine activity was detectable in any of the filtrates. In an attempt to reduce the adsorption of colicine by the filter, efforts were made to alter the charge on a series of pads by impregnating them with $0.01 \mathrm{M}$ or $0.1 \mathrm{M}$ solutions of phosphate

TABLE III

The colicine activities of successive fractions collected during Millipore filtration of a single sample of each of six colicine preparations

\begin{tabular}{|c|c|c|c|c|c|c|}
\hline \multirow{2}{*}{$\begin{array}{l}\text { Fraction } \\
\quad(2 \mathrm{ml})\end{array}$} & \multicolumn{6}{|c|}{ Colicine activity* of test preparation } \\
\hline & $\mathrm{A}-\mathrm{CA} 31 \uparrow$ & $\mathrm{B}-\mathrm{CA} 18$ & D-CA23 & $\mathrm{E}_{2}-\mathrm{CA} 42$ & $\mathrm{E}_{3}-\mathrm{CA} 38$ & $\mathrm{~K}-\mathrm{K} 235$ \\
\hline $\begin{array}{l}1 \\
2 \\
3 \\
4 \\
5 \\
6\end{array}$ & $\begin{array}{l}148 \cdot 0 \\
152 \cdot 6 \\
157 \cdot 1 \\
158 \cdot 4 \\
163 \cdot 3 \\
164 \cdot 2\end{array}$ & $\begin{array}{l}219 \cdot 4 \\
221 \cdot 1 \\
225 \cdot 4 \\
221 \cdot 0 \\
220 \cdot 3 \\
220 \cdot 1\end{array}$ & $\begin{array}{l}170 \cdot 1 \\
179 \cdot 3 \\
183 \cdot 1 \\
184 \cdot 6 \\
187 \cdot 3 \\
191 \cdot 6\end{array}$ & $\begin{array}{l}251 \cdot 1 \\
255 \cdot 6 \\
257 \cdot 3 \\
260 \cdot 2 \\
267 \cdot 5 \\
269 \cdot 3\end{array}$ & $\begin{array}{l}249 \cdot 8 \\
260 \cdot 3 \\
266 \cdot 6 \\
273 \cdot 1 \\
275 \cdot 4 \\
277 \cdot 5\end{array}$ & $\begin{array}{l}156 \cdot 7 \\
161 \cdot 3 \\
170 \cdot 2 \\
177 \cdot 5 \\
181 \cdot 5 \\
187 \cdot 6\end{array}$ \\
\hline Washings $\ddagger$ & $109 \cdot 2$ & $180 \cdot 8$ & $133 \cdot 2$ & $240 \cdot 7$ & $200 \cdot 3$ & $163 \cdot 1$ \\
\hline
\end{tabular}

* Colicine activity is shown as the average diameter of four replicate inhibition zones recorded in $\mathrm{cm} \times 10^{-2}$.

$\uparrow$ As in footnote to table $I$.

$\ddagger 2 \mathrm{ml}$ peptone water filtered after $12 \mathrm{ml}$ of the colicine sample.

buffer at $p \mathrm{H} 6 \cdot 5$. However, when cultures containing colicines were passed through these treated filter pads no colicine activity was ever detected in the filtrates.

Sterilisation by filtration through a Millipore filter was more satisfactory. Crude filtrates were active; consequently a quantitative investigation was undertaken in which 12-ml samples of preparations of each colicine were filtered and the filtrate collected as successive 2-ml fractions. After the whole colicine sample had been filtered, sterile peptone water was flushed through the same membrane and the filtrate collected.

When the filtered fractions from any colicine sample were assayed and compared, the activity of the first fraction was always lower than that of the sixth and last to be collected (table III). In general, there was an increase in the colicine content of successive fractions, the differences in recorded activity between fractions being greater than could be accounted for by the experimental error of the assay. The peptone water used to wash out the filter was found to have considerable colicine activity. With colicine $\mathrm{A}$ and $\mathrm{D}$ preparations, the activity of each sample sterilised by Millipore filtration was greater than that of 
a corresponding sample sterilised by heat or chloroform. The activity of each of the other colicine preparations after Millipore filtration was the same as that of corresponding samples that had been exposed to chloroform.

\section{Effect of sterilisation by ultraviolet light on colicine potency}

Up to $10-\mathrm{ml}$ amounts of colicine-containing fluids may be conveniently sterilised without loss of potency by exposure to ultraviolet light (see Methods). In the present experiments all the colicines were resistant to UV irradiation of up to 60 minutes' duration. Usually, such samples are sterile after exposure for 5 min., but occasionally we have found them to be contaminated with sporebearing organisms and these interfere with the assay of the colicine activity.

\section{Discussion}

The present work does not justify unequivocal recommendations for the sterilisation of cultures of colicinogenic members of the Enterobacteriaceae. Of the five methods investigated, two appear to be more or less unacceptableSeitz filtration removes colicine activity completely and the response of colicines to heat is idiosyncratic. It may be argued that the degree of inactivation of any colicine preparation is probably small when cultures are heated for only $5 \mathrm{~min}$. at $60^{\circ} \mathrm{C}$, but such minimally lethal conditions for coliform organisms can in practice be achieved reliably with small volumes only. With more vigorous or more prolonged heating, the differences between the sensitivities of individual colicines become more marked. There is evidence too that the thermostability of certain colicines may vary with the degree of chemical purification.

Millipore filtration and UV irradiation both yielded sterile preparations with virtually undiminished potency, as did exposure to chloroform provided that the duration of this treatment was kept as short as possible. No single method can be universally applied, for there are disadvantages associated with each.

It has been shown that although the colicines with which we have worked can pass through a sterilising Millipore membrane, some active material is temporarily bound to the filter bed, although it may easily be washed out. The increase in activity of successive filtrate fractions suggests that the retained colicines readily saturate the filters and when this occurs the colicine concentration on each side of the barrier seems to reach equilibrium. Millipore filtration is therefore probably more suitable for sterilising large volumes than very small amounts, for the latter may have significant proportions of colicine removed by adsorption.

Exposure to ultraviolet light is, in general laboratory practice, more suitable for sterilising small quantities as the layer of irradiated fluid should not exceed $2 \mathrm{~mm}$ in depth. A further disadvantage is the fact that the material must be uncovered during treatment and our preparations have occasionally been contaminated with spore-bearing organisms introduced when this method was used. However, with care, very satisfactory sterile preparations can be obtained after exposure for only $5 \mathrm{~min}$. 
Although $\mathrm{B}$ colicines and colicine $\mathrm{K}$ were progressively inactivated during prolonged contact with chloroform, the effect was barely significant within the period of $5 \mathrm{~min}$. that is required to ensure death of the colicine producers. It is recognised that chloroform-treated preparations of colicine $\mathrm{K}$ and B/TR24 were less active than those that had been heated, whereas chloroformed preparations of colicines $\mathrm{A}$ and $\mathrm{D}$ were somewhat weaker than comparable samples after Millipore filtration. On the other hand, chloroformed preparations of most B colicines and colicines $\mathrm{E}_{2}$ and $\mathrm{E}_{3}$ have been at least as active as any similar preparations sterilised by other methods. Despite these conflicting results, we prefer to use chloroform treatment for routine purposes and our choice is largely based on grounds of convenience; the method is very simple, it is suitable for both large and small samples and has consistently given satisfactory results.

Since the effect of heat has been used in differentiating certain colicines, some of our findings require brief comment. Hamon and Péron (1964) selected resistance to heat at $100^{\circ} \mathrm{C}$ for $5 \mathrm{~min}$. and susceptibility to heat at $60^{\circ} \mathrm{C}$ for $30 \mathrm{~min}$. as criteria defining the lower limit for thermoresistance and the upper limit for thermolability. Such a convention leaves a wide intermediate zone and our results, in common with those of Hauduroy and Papavassiliou (1962) and Reeves (1963), indicate that many colicines do not in fact exhibit extreme sensitivity or tolerance to heat. The recognition of this fact is clearly important when colicine activity can be recorded in quantitative terms; even when the response is simply expressed in quantal terms, e.g., as + or -, the results are likely to be affected by the initial colicine content of the samples. The effect of extraneous material may also be significant: thus our confirmation of the relative thermolability of colicine $\mathrm{A}$ in crude preparations (Fredericq and Betz-Barreau, 1948) is in apparent conflict with the report of Barry, Everhart and Graham (1963) who had worked with purified material. It may be that purification of a relatively thermostable colicine makes it more heat-stable and in our view this is not necessarily inconsistent with the claim of Nomura (1967) that the heat-lability of thermolabile colicines increases with the degree of purity of the colicine.

\section{SUMMARY}

Preparations of colicines $\mathrm{A}, \mathrm{B}, \mathrm{D}, \mathrm{E}_{2}, \mathrm{E}_{3}$ and $\mathrm{K}$ were exposed in separate experiments to chloroform, heat, filtration, and ultraviolet light and the effects were examined quantitatively.

Chloroform at a concentration of 5 per cent. ( $\mathrm{v} / \mathrm{v})$ sterilised preparations of each colicine within $5 \mathrm{~min}$. and there was an acceptably low degree of inactivation. Exposure for longer periods was associated with progressive inactivation of $\mathrm{B}$ colicines and colicine $\mathrm{K}$.

Millipore filtration and ultraviolet irradiation are slightly more effective but technically more exacting methods applicable to large and small samples respectively. Seitz filtration removed all detectable colicine activity.

Heating is not recommended as its effects on colicine activity are difficult to predict. The criteria of thermostability are discussed. 
This work was carried out while B. W. Senior held Science Research Council Studentship $\mathrm{B} / 65 / 1212$.

\section{REFERENCES}

Barry, G. T., Everhart, D. L., AND 1963. Nature, Lond., 198, 211.

GraHAM, M.

Clarke, C. H., and Macphee, D. G. . 1965. Experientia, 21, 18.

FASTIER, L. B. . . . . . . . . . . 1949. J. Immun., 62, 399.

Frederice, P. . . . . . . . . 1957. A. Rev. Microbiol., 11, 7.

, . . . . . . . 1963. Ergebn. Mikrobiol. ImmunForsch. exp. Ther., 37, 114.

FredericQ, P., and Betz-Barreau, M. . 1948. C.r. Séanc. Soc. Biol., 142, 1078.

Hamon, Y., And Péron, Yvonne . . 1959. Annls Inst. Pasteur, Paris, 97, 518.

" " , ", $\quad$. . 1961. Ibid., 100, 818.

" $", \quad " \quad$ "

" $", \quad, \quad$ " $\quad$. . . 1964. Ibid., 107, 44.

" $\quad ", \quad ", \quad$. . . 1966. Ibid., 110, 389.

Hauduroy, P., and Papavassiliou, J. . 1962. Ibid., 102, 644.

Heatley, N. G., AND FloRey, H. W. 1946. Br. J. Exp. Path., 27, 378.

KeEne, J. H. . . . . . . . . . . 1966. Canad. J. Microbiol., 12, 425.

Kellenberger, G., ANd Kellenberger, 1956. Schweiz. Z. allg. Path. Bakt., 19, 582. E.

Matsushita, H., Fox, M. S., AND Goebel, 1960. J. Exp. Med., 112, 1055.

W. F.

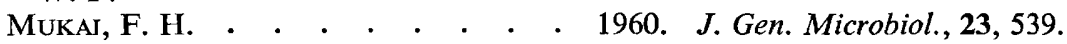

Nomura, M. . . . . . . . . 1967. A. Rev. Microbiol., 21, 257.

Papavassiliou, J. . . . . . . . . 1961. Nature, Lond., 190, 110.

ReEVes, P. R. . . . . . . . . 1963. Austral. J. Exp. Biol. Med. Sci., 41, 163.

Richardson, H., EMslie-Smith, A. H., 1968. Appl. Microbiol., 16, 1468.

AND SENIOR, B. W. 